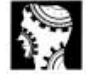

original papers
12 Kelly L, Regan L, Burton S. An Exploratory Study of the Prevalence of Sexual Abuse in a Sample of $16-21$ Year Olds. University of North London, 1991.

13 López F, Carpintero E, Hernàndez $A$ Martín, MJ, Fuertes A. Prevalence and sequelae of childhood sexual abuse in Spain. Child Abuse Neg/1995; 19 : 1039-50.

14 Windle M, Windle R, Scheidt DM Miller GB. Physical and sexual abuse and associated mental disorders among alcoholic in-patients. Am J Psychiatry 1995; 152: 1322-8.

15 MoncrieffJ, Drummond DC Candy B, Checinski K, Farmer R. Sexual abuse in people with alcohol problems. A study of the prevalence of sexual abuse and its relationship to drinking behaviour. BrJ Psychiatry 1996; 169: 355-60.
16 Stone EA. Childhood Sexual Abuse and Substance Misuse (MSC dissertation). Imperial College London, 2005.

17 Horowitz M, Wilner N, AlvarezW. Impact of Events Scale. Psychosom Med 1979; 41: 209-18.

18 Sundin EC, Horowitz ML. Horowitz's Impact of Event Scale evaluation of 20 years of use. Psychosom Med 2003; 65 $870-6$.

19 National Institute for Health and Clinical Excellence. Management of Post-Traumatic Stress Disorder in Adults in Primary, Secondary and Community Care. Clinical guideline 26. NICE, 2005

20 CornielW, Beaton R, Murphy S, Johnson C, Pike K. Exposure to traumatic incidents and prevalence of post-traumatic stress symptomatology in urban firefighters in two countries. J Occup Health Psychol 1999; 4 $131-41$

21 Mol SSL, Arntz A, Metsemakers JM, Dinant G-J,Vilters-van Montfort PAP, Knottnerus JA. Symptoms of post-traumatic stress disorder after non-traumatic events: evidence from an open population study. BrJ Psychiatry 2005; 186: 494-9.

22 Rosen GM, Spitzer RL, McHugh PR Problems with the post-traumatic stress disorder diagnosis and its future in DSM-V. BrJ Psychiatry 2008; 192: 3-4.
23 Triffleman EG, Marmar CR, Delucchi $\mathrm{KL}$, Ronfeldt $\mathrm{H}$. Childhood trauma and PTSD in substance abuse inpatients. J Nerv Ment Dis 1995; 183: $172-6$.

24 Ouimette PC, Brown KT, Najavits LM. Course and treatment of patients with both substance use and posttraumatic stress disorders. Addict Behav 1998; 23: 785-95.

25 Alcohol Concern. Mental Health and Alcohol Misuse Project, Factsheet 6: Post-Traumatic Stress Disorder and Alcohol. Alcohol Concern, 2004 (http:// www.alcoholconcern.org.uk/ files/20040709.145809. ptsd\%20factsheet.pdf).

Shaheen Shora Specialist Registrar, Barnet, Enfield and Haringey Mental Health NHS Trust, Chase Farm Hospital, Enfield, Elizabeth Stone Associate Specialist, New House Drug and Alcohol Unit, Shelton Hospital, Shrewsbury, * Keron Fletcher Consultant Addictions Psychiatrist, New House Drug and Alcohol Unit, Shelton Hospital, Shrewsbury SY3 8DN, email: keron.fletcher@sssft.nhs.uk

\title{
Service user perspectives on the content of the undergraduate curriculum in psychiatry
}

\section{AIMS AND METHOD}

To explore user perspectives on the content and delivery of the undergraduate curriculum in psychiatry. The study design was qualitative and used focus groups. Four focus groups were run with a total of 28 participants.

\section{RESULTS}

The key finding was that participants were clearer about the attitudes they felt students should convey than they were about the skills and knowledge required.

\section{CLINICAL IMPLICATIONS}

Service user perspectives on the content of the undergraduate psychiatry curriculum need to be considered as curricula are developed.
The undergraduate curriculum is the first step to ensuring that graduating doctors are equipped with the essential skills and appropriate respectful attitudes that are associated with professionalism. Given the current statistic that one in four people has mental health problems at some time during their life, ${ }^{1}$ doctors are likely to encounter mental health problems irrespective of which speciality they choose. Currently, only a small fraction of the undergraduate medicine course concentrates on the teaching of psychiatry (in some cases as little as 2 weeks). ${ }^{2}$

The Royal College of Psychiatrists ${ }^{3}$ now requires user and carer involvement in postgraduate education and, in line with recommendations in The National Service Framework for Mental Health, ${ }^{4}$ it is appropriate for service users to be involved in planning and providing the content of the undergraduate curriculum.

Service users and carers have had increasing input into health and social care education at a range of levels including medical training (e.g. Livingston \& Cooper, ${ }^{5}$ Tew et $a^{6}{ }^{6}$. Their role in delivering recommendations from
Tomorrow's Doctors ${ }^{7}$ that students need guidance on 'Communicating with people with mental illness including where patients have special difficulties in sharing how they feel and think with doctors' is evident. There is growing recognition of the spectrum of ways in which service users and carers can contribute to education. ${ }^{8}$ Fadden et al ${ }^{9}$ discuss four approaches to involvement in the training of psychiatrists: course planning, sharing experiences and perspectives, commenting on assignments and involvement in the selection of trainees. With a notable exception, ${ }^{10}$ however, there has been very little systematic evaluation of the impact of involving people with direct experience of mental ill health as teachers and tutors. Recent studies have found that trainees are generally enthusiastic about patients contributing to their education and assessments although fears were expressed about the latter. ${ }^{11,12}$ More has been written about service user involvement with psychiatric trainees than with medical students and their roles as teachers have been more widely explored than their potential contributions to curriculum development. 
The main study explored service user perspectives on both the content and process of medical students' learning about psychiatry, and in this paper we report on the findings relating to content, having already reported on the roles of service users in undergraduate psychiatry. ${ }^{13}$

\section{Method}

Following discussion with user representatives the method used to elicit service user perspectives was focus groups. Focus groups are a way of listening to people and learning from them through creating a line of communication, and are particularly suitable for vulnerable participants in the study. ${ }^{14}$ The method allows group members to react to and build upon the responses of others, with the potential development of ideas that might not be uncovered in individual interviews.

The schedule for the focus groups was developed by modification of semi-structured interviews used in similar work elsewhere. ${ }^{15}$ Four service user groups were identified through the Mental Health in Higher Education Project and personal contacts. The contact person for each of these groups was identified as a user lead. The roles of the contact person was locally variable but for all they included representing service user perspectives (on behalf of their group) to external agencies. User leads were sent the schedule ahead of the focus groups and invited to suggest changes.

\section{Procedure}

All four groups identified saw collaboration with research as one aspect of their role. As participants were being interviewed as members of the group, and not as patients, ethical approval was not required. The project was discussed with the research office, however. Each group leader was asked to identify six to eight participants who would be willing to participate. No specific exclusion or inclusion criteria were given. The service user lead issued an invitation to their members. The date, time and health status of invitees influenced those who eventually participated. All the focus groups took place in locations familiar to the service user groups and lasted between 90-120 min. The same moderator (N.D.) oversaw all focus groups. Although there was a focus group schedule, the participants were encouraged to raise and discuss their own ideas pertaining to key areas under exploration. Some of the group members were familiar with each other and used to discussion forums. Participants were paid travel expenses and a standard fee. The sessions were audiotaped, with consent, and the tapes transcribed.

\section{Sample}

All four focus group leads who were contacted agreed to participate. The total sample (over all the groups) consisted of 16 men and 12 women. All were White adults with experience of adult mental health services; two also had experience of services for older people and two women had used mental health services as children. There was one carer who cared for her husband who had mental health problems. The respondents had a range of mental health diagnoses, as evidenced through the transcripts, and all were generally well when they participated. In one group, a young man with substance misuse problems left the focus group as he felt unable to continue.

\section{Analysis}

All the focus group tapes were transcribed verbatim. Thematic analysis was undertaken. ${ }^{16}$ N.D. and R.E. identified themes independently before discussion to reach agreement on those of relevance to the research question. This procedure helped to ensure reliability. Themes were compared across scripts to develop conceptual ideas beyond description, and these were then categorised.

\section{Results}

In this paper we report in detail on the themes relating, on the one hand, to the content of curricula and, on the other, to how such content should be taught. All participants welcomed the opportunity to participate in the research, and viewed their input as valued and progressive:

I think training has got better and the fact that we're having this meeting shows that things are moving.

There was little variation between the groups in the attitudes they thought were appropriate. There was more variation in the depth of knowledge and skills considered necessary for graduating doctors. The key themes relating to the educational outcomes were categorised into attitudes, knowledge and skills.

\section{What should students be taught? \\ Attitudes}

Attitudes are difficult to identify and tend to be conveyed through specific behaviours. Behaviours described by the focus groups, that were taken to relate to attitudes, are described in this section.

- Interpersonal qualities such as caring, listening, spending time, being non-judgemental.

- Valuing and respecting patients; seeing the patient as a whole person: demonstration of non-stigmatising behaviour and non-stereotypical views of patients with mental illness.

- Empathy and sympathy.

- Conveying hope and a positive outcome.

- Respect for diverse perspectives such as spirituality and homeopathy (alternative medicine).

- Accepting they have their own limitations and valuing teamwork.

There was a clear view that users place high value on doctors presenting themselves as 'human' and being able 
to talk to patients as people. This view was held by some to be of even greater importance than having knowledge about psychiatric conditions.

original

papers
I couldn't care less really whether they knew about it or not, what I care about is how well they can listen to me and treat what I had to say with respect, and acknowledge that I'm an expert in what's going on with me...

Participants clearly wanted to be shown respect and did not like to be treated 'differently' from anyone else. They were keen to stress that they wanted to be treated as an equal, be valued and respected as an individual. Alongside valuing and respecting patients, some users were keen for doctors to recognise the value of patients' knowledge and involve them in the management of the problem. One interviewee commented:

I know what symptoms I had and I know that they're sometimes different to the normal symptoms.

When their doctor told them what the symptoms were and that they didn't have them, they felt they weren't being listened to:

I had other symptoms, they're my signposts.

All participants felt that doctors needed more awareness of mental health issues. From some, there was a request for doctors to have a good understanding of mental health problems in order to show understanding and be empathetic towards them.

The adverse impact on users of a negative approach to mental health led to identification of the need for a positive attitude in doctors.

I think students should be encouraged to be positive rather than negative 'cos when you're ill, when you hear something negative, you just clam up and feel worse... a small point can lift you.

An example of a negative approach that was felt to be unhelpful was:

A lot of psychiatrists still have this idea that if you've got schizophrenia it's going to be deteriorating and you're going to just get worse and worse.

Some of the attitudes identified as important were generic to all specialties and not just psychiatry. Respect for diversity was one of these areas, particularly with respect to spiritual and religious beliefs. There was a view that students sometimes needed better preparation before being expected to address their own fears about mental health.

Some students were saying they were placed on psychiatric wards and they hadn't really had much briefing beforehand and they found it really, really frightening ... they didn't know how to relate to patients.

Many of the fears and uncertainties doctors face in relation to people with mental health problems are viewed as being related to a lack of knowledge of psychiatric disorders. There was a view that doctors should 'learn to recognise what mental health is, as opposed to mental illness, and start with themselves'.

\section{Knowledge}

There was little discussion about specific content within these 'knowledge' themes. When content was raised, it reflected personal experience of having received poor care in that area (e.g. side-effects of medication). However, one example showed that knowledge is about more than the clinical aspects of a mental illness; it also relates to knowledge about public understanding of terminology used to describe the illness.

I just wanted to say something specific about stigma and schizophrenia, it's just that schizophrenia's in a strange position because the word as it's used in ordinary language means something different to how it's used as a medical term.

Specific knowledge areas that arose in the discussion included knowing about different presentations of mental illness, psychotropic medication and its side-effects, and service design.

\section{Skills}

- Effective at engaging patients and developing a partnership with them.

- Good and effective communication skills.

- Basic counselling skills: effective at listening, seen as being there for the patient.

- Making an assessment, being able to diagnose and manage the problem.

There was a clear view that the doctor's skill in developing meaningful partnerships with patients was important, particularly with regard to patient involvement in the management of their illness. There were some service users who want to be involved in decisionmaking, whereas others want professionals to be directive:

I had to ask for a sick note for work and he actually asked me 'how long do you need?'. I thought, well, you're the doctor; presumably you might have some idea of how long these things last.

In order to engage individuals, it was recognised that doctors need good communication skills. Some of these skills relate to language itself:

Thinking about the language that you use, how you use it, who you're using it with but making sure that you're actually setting up a dialogue as opposed to telling somebody.

Communication skills were also seen as essential for teamwork with other team members providing care (including effective communication between primary and secondary providers). Counselling skills are inextricably linked to perceived attitudes of the doctor and their impact on the patient. Active listening was identified as key:

They [doctors] don't actually have to cure it, they can just sit there and listen to you and that actually might be all you need, not being frightened by the emotion or distress that can come out.

The importance of clinical skills, when these were mentioned, was nearly always tied up with the importance of a positive attitude of the doctor:

When I'm ill, I want a good technician there and a good human being who's going to help me. 


\section{The organisation and delivery of teaching}

The main findings that arose with respect to teaching were:

- teaching on mental health should be integrated and early in the course (with a view to addressing negative attitudes);

- teaching of mental health should be recurring;

- more time should be given to this area than is currently devoted to it:

- participants questioned the value of students sitting in out-patient clinics and 'just observing'.

Such views were grounded in participants' own experiences, and their view that many doctors are simply not adequately aware of mental health problems and their impact on individuals. There was some agreement that psychiatry should be taught in recurring blocks of time, rather than individual days spread over a longer period of time. In addition, it was felt that students need to explore their own perceptions of mental health, as well as attitudes and prejudices towards mental ill health. This should be done as a priority in the early stages of their training.

There was much concern that in some medical schools the teaching of psychiatry was optional and delivered over a very short period. One service user felt that all doctors should have 6 months basic training in mental health, whereas another felt that as much as 50\% of training should relate to mental health, given that a large percentage of people visiting their general practitioner (GP) do so with mental health issues. Although this might be a tall order for medical schools to deliver, there was a suggestion that some of this teaching could be provided by exploiting the expertise available in general practice.

They could tap into things like mental health practitioners and mental health workers now attached to GP surgeries. Where we are, the PCTs [primary care trusts] actually in CAMHS [children and adolescent mental health services], picking out certain GPs who have an expertise and an interest and trying to develop links with them and using them in training.

Where service users are involved in teaching, it was felt that the main benefit derived from them sharing their own experience and not from their identity as a representative of a particular organisation or mental health charity. One user was adamant that consultant psychiatrists have an important role to play in teaching clinical psychiatry.

One service user described the effective use of reflective e-portfolios in the second year of medical teaching. In this, exposure to different patients and the impact on students' emotions and thoughts about mental health could be reflected upon and documented. This was considered to be useful when followed up by one-to-one or small group discussion with a tutor.

There was consensus that medical education and the training of doctors had changed for the better although there was still progress to make.

\section{Discussion}

This study has confirmed some previous findings about what service users want from professionals who provide care and support - good and effective communication skills, an ability to listen, to make a holistic assessment and to work in partnership. These fundamentals have been acknowledged in guidance on the development of undergraduate medical curricula., 7,

This study has identified the emphasis that service users place upon the development of interpersonal qualities; prized, by some, even over and above the need for knowledge about mental disorders. There were strong feelings too about the need for an awareness of the stigma and discrimination associated with mental ill health - to be acquired from an early stage of training, so that young doctors can recognise the effects of stigma as well as counter their own prejudices and misconceptions about mental ill health.

Service users in this study also felt that doctors need to understand what constitutes good mental health before they can build their knowledge and understanding of mental ill health. Although medical training as a whole tends to begin with a focus on health and move to an understanding of ill health, in mental health teaching, the converse can be true. Given the increasing levels of mental ill health among students and doctors, a focus on issues of 'self' and 'self-care' may, as one participant suggested, be a helpful starting point.

A key finding of the study was the need for medical students to 'learn' or develop specific attitudes. Whether attitudes can be learnt, or whether they are an innate attribute, is open to debate but we do know that attitudes are portrayed by behaviour. The medical school curriculum could, therefore, develop self-awareness about how the student doctor's behaviour may be interpreted, especially by particularly vulnerable individuals with mental health problems. Attitudinal behaviour displayed by doctors may be influenced by having to deal with the unknown - being afraid and not knowing how to develop a professional relationship with a person with mental health problems. Involvement with mental health service users may allay this fear, and involvement of service users and carers in delivering the curriculum may provide the powerful influence that is required.

The undergraduate curriculum is already crowded but clearly it was felt that more time should be given to psychiatry than is currently provided, and coverage should be compulsory, not optional. All doctors will meet patients with mental ill health and lack of knowledge and understanding will impede their ability to take a holistic approach to patient care. It is of particular note that the participants lacked clarity about the knowledge required but this is not to say that they deemed knowledge or skills as less important.

\section{Limitations of the study}

There was no representation of minority ethnic groups in the focus groups and this may have resulted in less of a focus on cultural issues than might otherwise have been original papers 
the case. In one of the groups the issue of tailored and individual care was discussed, however. The participants in this group were clear that doctors still had much to learn through working alongside patients, rather than being focused solely on issues judged by professionals to be important. Limitations on time and resources precluded, in this instance, focus groups with carers. They too have a valuable contribution to make to these debates. This small study indicates that the service user role in curriculum design and delivery warrants further exploration

\section{Conclusion}

That service users have relevant and helpful perspectives to share is clear from this research. At a local level, service user focus groups may prove one way forward in enhancing programme planning. It does appear from this study that service users are clearer about the attitudes that they expect doctors to convey than the knowledge and skills that they expect them to have.

\section{Acknowledgements}

We would like to thank the Medicine, Dentistry and Veterinary Medicine subject centre of the Higher Education Academy for support in funding the focus groups. All the authors are independent from the funding body. We would also like to thank all the participants for their active involvement and hospitality: without their support we would not have been able to undertake this work. The Making Waves organisation wished for their organisation to be acknowledged by name. In the paper, all personal identifiers have been removed or disguised so the individuals described are not identifiable and cannot be identified through the information given.

\section{Declaration of interest}

None.

\section{References}

1 The Office for National Statistics. Psychiatric Morbidity Report. ONS, 2001

2 Karim K, Anderson I, DaviesT, Lindsay J, Edwards R, Dogra N, et al. A survey of the teaching and assessment of undergraduate psychiatry in the medical schools of the United Kingdom and Ireland. Undergraduate psychiatry: what's going on. Med Teach 2009; in press.

3 Royal College of Psychiatrists. Partners in Care. Royal College of Psychiatrists, 2005.

4 Department of Health. The National Service Framework for Mental Health. Department of Health 1999.

5 Livingston G, Cooper C. User and carer involvement in mental health training. Advan Psychiatr Treat 2004; 10: 85-92.

6 Tew J, Gell C, Foster S. Learning from Experience: Involving Service Users and Carers in Mental Health Education and Training. Mental health in higher education, 7 . National Institute for Mental Health in England (West Midlands) Trent Workforce Development Confederation, 2004.

7 General Medical Council. Tomorrow's Doctors. GMC, 2002

8 Wykurz G, Kelly D. Developing the role of patients as teachers: literature review. BMJ 2002; 325 $818-21$

9 Fadden G, Shooter M, Holsgrove G. Involving carers and service users in the training of psychiatrists. Psychiatr Bull 2005; 29: 270-4.

10 Barnes D, Carpenter J, Bailey D. Partnerships with service users in interprofessional education for community mental health: a case study. J Interprof Care 2000; 14: 189-200.

11 Vijayakrishnan A, Rutherford J, Miller S, Drummond LM. Service user involvement in training: the trainees' view. Psychiatr Bull 2006 30. $303-5$.

12 Babu KS, Law-Min R, AdlamT, Banks V. Involving service users and carers in psychiatric education: what do trainees think? Psychiatr Bull 2008 32: $28-31$.

13 Dogra N, Anderson J, Edwards R, Cavendish S. Service user perspectives about their roles in undergraduate medical training about mental health. Med Teach 2008; 30: e152-6

14 Robson C. Real World Research (2nd edn). Blackwell Publishers, 2002

15 Dogra N, Conning S, Gill PS, Spencer J,Turner M. Teaching of cultural diversity in medical schools in the United Kingdom and Republic of reland: cross sectional questionnaire survey. BMJ 2005; 330: 403-4

16 Joffe H, Yardley L. Content and thematic analysis. In Research Methods for Clinical and Health Psychology (eds DF Marks \& L Yardley): 56-68. Sage Publications, 2004

17 General Medical Council. Strategic Options for Undergraduate Medical Education. General Medical Education Committee Consultation. GMC, 2003.

*Nisha Dogra Senior Lecturer in Child and Adolescent Psychiatry, The Greenwood Institute of Child Health, University of Leicester, Westcotes House, Westcotes Drive, Leicester, LE3 0QU, email: nd13@le.ac.uk, Sue Cavendish Quality Management, Regulation and CapacityAdvisor, Leicestershire, Northamptonshire and Rutland HealthcareWorkforce Deanery, Jill Anderson Senior Project Development Officer, Mental Health in Higher Education, Lancaster University, Ruth Edwards Research Associate, Leicester University 